\title{
Biocomposites from polyhydroxybutyrate and bio-fillers by solvent casting method
}

\author{
GULSEN UZUN and DENIZ AYDEMIR* (D) \\ Faculty of Forestry, Forest Products Engineering, Bartin University, 74100 Bartin, Turkey
}

MS received 5 April 2016; accepted 2 July 2016

\begin{abstract}
Biocomposites from polyhydroxybutyrate (PHB) and some bio-fillers such as lignin (L), alpha cellulose (AC) and cellulose nanofibrils (CNFs) were prepared to investigate the effect of the bio-fillers on the properties of PHB by a solvent casting method. The thermal properties by thermogravimetry analysis (TGA-DTG and DTA) and differential scanning calorimetry (DSC) were determined; morphological characterization by scanning electron microscopy (SEM) and structural analysis by X-ray diffraction (XRD), and Fourier transform infrared spectroscopy (FTIR) of the biocomposites were performed. TGA curves showed that the highest values for $T_{10 \%}$, $T_{50 \%}$ of the biocomposites were $278.2^{\circ} \mathrm{C}$ for $\mathrm{PHB}+2 \% \mathrm{AC}$ and $291.7^{\circ} \mathrm{C}$ for $\mathrm{PHB}+2 \% \mathrm{CNFs}$; however, the best value for $\boldsymbol{T}_{75 \%}$ was obtained as $381.5^{\circ} \mathrm{C}$ for $\mathrm{PHB}+2 \% \mathrm{~L}$. According to DTG curves, the best results were found for $\mathrm{PHB}+\mathbf{0 . 5 \%} \mathrm{L}$ and $\mathrm{PHB}+\mathbf{0 . 5} \% \mathrm{CNFs}$. DTA showed an increase in temperature of maximum degradation with loading of lignin and CNFs. The addition of bio-fillers increases $T_{\mathrm{c}}$ and $T_{\mathrm{m}}$ for both first cooling/heating and second cooling/heating. $T_{\mathrm{c}}$ and $T_{\mathrm{m}}$ values for first cooling/healing were found to be lower as compared with second cooling/healing. Furthermore, the addition of bio-fillers acts as a nucleating agent in PHB and SEM pictures showed the porous structure in all biocomposites. SEM images revealed uniform distribution of the reinforcing particles in the polymer at low loadings $(0.5 \mathrm{wt} \%)$, while higher loadings $(2 \mathrm{wt} \%)$ of $\mathrm{L}$ and CNFs contributed to easy aggregation within the PHB matrix. In XRD studies, PHB in the range 5-55 shows 6 main peaks. XRD patterns of the PHB biocomposites revealed 3 main peaks at $13.57^{\circ}, 16.87^{\circ}$ and $22.1^{\circ}$, and the other peaks disappeared in the patterns. The largest and lowest values of $X_{\mathrm{c}}$ were found for $\mathrm{PHB}+2 \% \mathrm{AC}$ and $\mathrm{PHB}+2 \% \mathrm{CNFs}$, respectively.
\end{abstract}

Keywords. Polyhydroxybutyrate; solvent casting; bio-fillers; biocomposites; biopolymer.

\section{Introduction}

Plastics, which are derived from petroleum and not readily biodegradable, are used to produce many materials, and the plastic waste disposal has particularly increased in the packaging applications from day to day [1]. However, the consumption of these plastics caused a major disadvantage, resulting in air pollution because of their inherent toxicity, and there are large damages to natural life by contamination of oceans, seas and rivers [2]. The development and production of bioplastics from renewable resources have been started because of the environmental impact of plastics and the studies conducted on the eco-friendly and non-toxic alternatives to conventional petrochemical-derived plastics $[3,4]$.

Biopolymers can be obtained from renewable resources, synthesized microbially or synthesized from petroleumbased chemicals. The most abundant biopolymers based on renewable resources are polylactic acid (PLA), poly(3hydroxybutyrate) (PHB) and polycaprolactone (PCL) [5]. $\mathrm{PHB}$ has attracted great scientific and industrial attention due

*Author for correspondence (denizaydemir@bartin.edu.tr) to its specific properties-biodegradability and biocompatibility, which are the reason for a wide range of untraditional applications of polymers [6,7]. PHB has properties similar to those of polypropylene; however, its high melting temperature of $170^{\circ} \mathrm{C}$ complicates the processing of PHB [8,9]. An important advantage of this polymer is its water vapour barrier property, usefully as films [7,10]. One of the major disadvantages of PHB is its poor mechanical properties and brittleness/fragility. In order to remove this disadvantage, there are some reports on reinforcing effects of bio-fillers/ particles in PHB. Reinforcements of bio-fillers in PHB like wood flour [11], wood fibre [12], cellulose fibre [5,13-16], microcrystalline cellulose [17], cellulose nanowhiskers [18], lignocelluloses [19], lignophenols [20], etc. have also been reported. These studies showed that the addition of low percentages of bio-fillers has positive effects on the structural properties of the PHB.

The aim of this work was to investigate the crystalline structure, morphological and thermal properties of $\mathrm{PHB}$ with cellulose nanofibril (CNFs), alpha cellulose (AC) and lignin (L) in the biocomposites using differential scanning calorimetry (DSC), thermogravimetric analysis (TGADTG), Fourier transform infrared spectroscopy (FTIR) and wide-angle X-ray diffraction (XRD). 


\section{Materials and methods}

\subsection{Materials}

Lignin (L), CNFs and $\mathrm{AC}$ were used to reinforce $\mathrm{PHB}$ matrix. $\mathrm{L}$ and $\mathrm{AC}$ fillers were of Beech (Fagus orientalis $\mathrm{L}$.) wood TAPPI T222 om-02 (2002) and TAPPI T212 om-02 (2002), respectively. L particles were then shredded to microsize to obtained better particle size with a mechanical grinder. CNFs were supplied from Graphene Chemical Inc. (Turkey). PHB as a polymer matrix was obtained from GoodFellow.

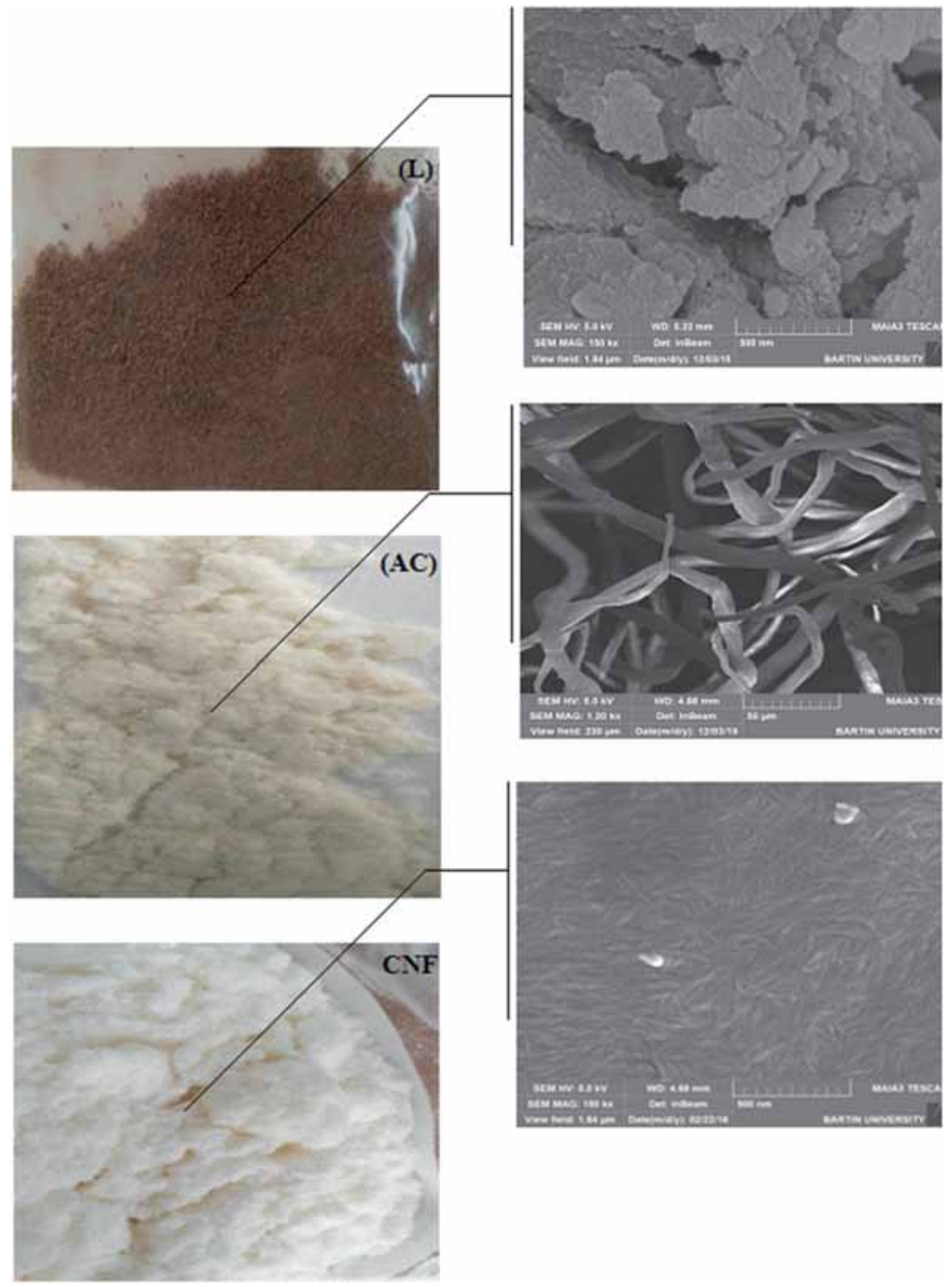

Figure 1. Scanning electron microscopy images of the reinforcing fillers. 
Density of PHB was $1.25 \mathrm{~g} \mathrm{~cm}^{-3}$. The reinforcing fillers are shown in figure 1.

PHB is a natural thermoplastic polyester that is produced by bacterial fermentation [9] and degrades fully in the environment without forming any toxic products [1]. PHB has a very high potential for industrial applications due to its high crystallinity (50-70\%), excellent gas barrier and physical properties. Some important properties of PHB matrix are given in table 1.

Table 1. Some properties of PHB [34].

\begin{tabular}{lc}
\hline Properties & Values \\
\hline Melting temperature, $T_{\mathrm{m}}\left({ }^{\circ} \mathrm{C}\right)$ & 180 \\
Tensile strength $(\mathrm{MPa})$ & 40 \\
Tensile modulus $(\mathrm{MPa})$ & 2500 \\
Glass transition temperature, $T_{\mathrm{g}}\left({ }^{\circ} \mathrm{C}\right)$ & $4-5$ \\
Density $\left(\mathrm{g} \mathrm{cm}^{-3}\right)$ & 1.25 \\
Crystallinity $(\%)$ & $60-80$ \\
Elongation at break $(\%)$ & 6 \\
Flexure modulus $(\mathrm{GPa})$ & 3.5 \\
Izod impact strength $\left(\mathrm{J} \mathrm{m}^{-1}\right)$ & $35-60$ \\
\hline
\end{tabular}

Table 2. The formulation used and loading rates of PHB biocomposites.

\begin{tabular}{lcccc}
\hline Formulations & PHB (\%) & NCC (\%) & AC (\%) & L (\%) \\
\hline Pure PHB & 100 & - & - & - \\
PHB+0.5\%AC & 99.5 & - & 0.5 & - \\
PHB+2\%AC & 98 & - & 2 & - \\
PHB+0.5\%CNFs & 99.5 & 0.5 & - & - \\
PHB+2\%CNFs & 98 & 2 & - & - \\
PHB+0.5\%L & 99.5 & - & - & 0.5 \\
PHB+2\%L & 98 & - & - & 2 \\
\hline
\end{tabular}

\subsection{Preparation of bio-fillers/PHB biocomposite films}

PHB and PHB biocomposite films were prepared using a solvent casting method with small modifications. The formulations used and the loading rates for the biocomposites are presented in table 2 .

PHB (5 g) dissolved in chloroform $(100 \mathrm{ml})$ was strongly mixed for $30 \mathrm{~min}$ at room temperature $\left(25 \pm 2^{\circ} \mathrm{C}\right)$ with a magnetic stirrer. The blends obtained were poured into Petri dishes and dried at room temperature for $24 \mathrm{~h}$ under an airhood. The dried PHB films were then removed from the Petri's surface. In the preparation of the PHB biocomposites, AC, L and CNFs at low (0.5\%) and high (2\%) loadings were suspended in chloroform under magnetic stirring for $15 \mathrm{~min}$. The blends were then sonicated for $15 \mathrm{~min}$ at room temperature with an ultrasonic mixer at $50 \mathrm{~W}$ and $50 \%$ frequencies. The solutions containing 0.5 and $2 \mathrm{wt} \%$ of $\mathrm{AC}, \mathrm{L}$ and CNFs were added to the previously prepared PHB solution and then stirred vigorously for $15 \mathrm{~min}$ with a magnetic stirrer. The blends were sonicated for another $15 \mathrm{~min}$, and then put into Petri dishes. The final films were obtained by the procedure explained above for pure PHB films. After drying at room temperature for $24 \mathrm{~h}$ under the air-hood, all PHB composite films were placed in a condition chamber.

\subsection{Characterization and testing}

2.3a Thermogravimetric analysis (TGA/DTG-DTA): Thermal stability test was carried out using a Perkin Elmer analyzer on samples of about $5 \mathrm{mg}$. Each sample was scanned over a temperature range from room temperature to $600^{\circ} \mathrm{C}$ at a heating rate of $10^{\circ} \mathrm{C} \mathrm{min}^{-1}$ under nitrogen with a flow rate $20 \mathrm{ml} \mathrm{min}^{-1}$ to avoid sample oxidation. The degradation temperature for weight loss at 10, 50, 75 and $90 \%\left(T_{10 \%}\right.$, $T_{50 \%}, T_{75 \%}$ and $T_{90 \%}$ ) was also calculated. Dynamic thermal

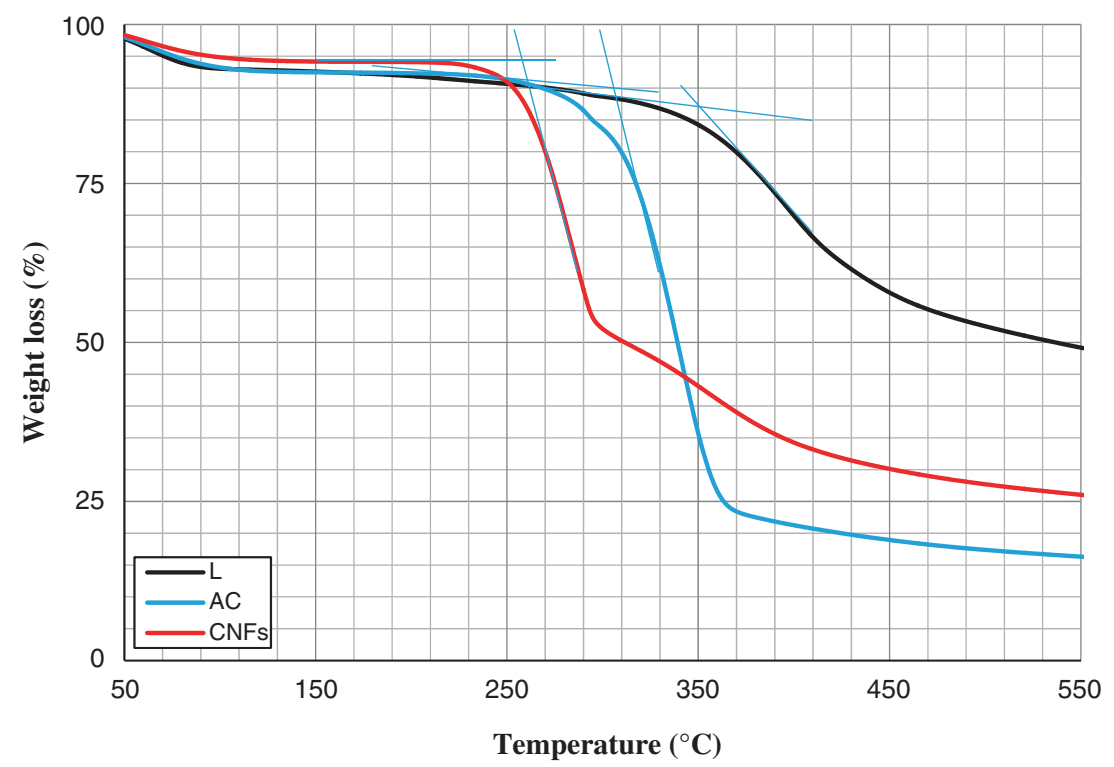

Figure 2. Weight loss percentage of bio-fillers during thermal test. 
analysis (DTA) curves were determined using a TGA analyser. $T_{\mathrm{m}}$ (melting temperature) and $T_{\mathrm{d}}$ (degradation temperature) were also measured from the DTA curves.

2.3b Differential scanning calorimetry (DSC): DSC was conducted using the Perkin Elmer analyzer on samples of about $5 \mathrm{mg}$. All samples were held at $20^{\circ} \mathrm{C}$ for $5 \mathrm{~min}$, heated at a rate of $10^{\circ} \mathrm{C} \mathrm{min}^{-1}$ to $300^{\circ} \mathrm{C}$, subsequently held for $5 \mathrm{~min}$ to erase thermal history, then cooled at a rate of $10^{\circ} \mathrm{C}$ $\min ^{-1}$ to $20^{\circ} \mathrm{C}$, subsequently held for $5 \mathrm{~min}$ and heated again at a rate of $10^{\circ} \mathrm{C} \mathrm{min}^{-1}$ to $300^{\circ} \mathrm{C}$ under a nitrogen atmosphere with $30 \mathrm{ml} \mathrm{min}^{-1}$ flow rate. Melting temperature $\left(T_{\mathrm{m}}\right)$, crystallization temperature $\left(T_{\mathrm{c}}\right)$, melting enthalpy $\left(\Delta H_{\mathrm{m}}\right)$, crystallization enthalpy $\left(\Delta H_{\mathrm{c}}\right)$ and crystallinity $\left(X_{\mathrm{c}}\right)$ were calculated. The specimens' $X_{\mathrm{c}}$ was calculated according to the following equation [21,22]:

$$
X_{\mathrm{c}}=\frac{\Delta H_{\mathrm{f}}}{w \Delta H_{\mathrm{f}}^{0}} \times 100
$$

where $\Delta H_{\mathrm{f}}$ is the heat of fusion of the PHB composites, $\Delta H_{\mathrm{f}}^{0}$ the heat of fusion for $100 \%$ crystalline PHB $\left(\Delta H_{100 \%}=\right.$ $146 \mathrm{~J} \mathrm{~g}^{-1}$ ) and $\omega$ is the mass fraction for PHB in the composites [21,22].

2.3c Scanning electron microscopy (SEM): The morphological analysis of the biocomposites was performed by

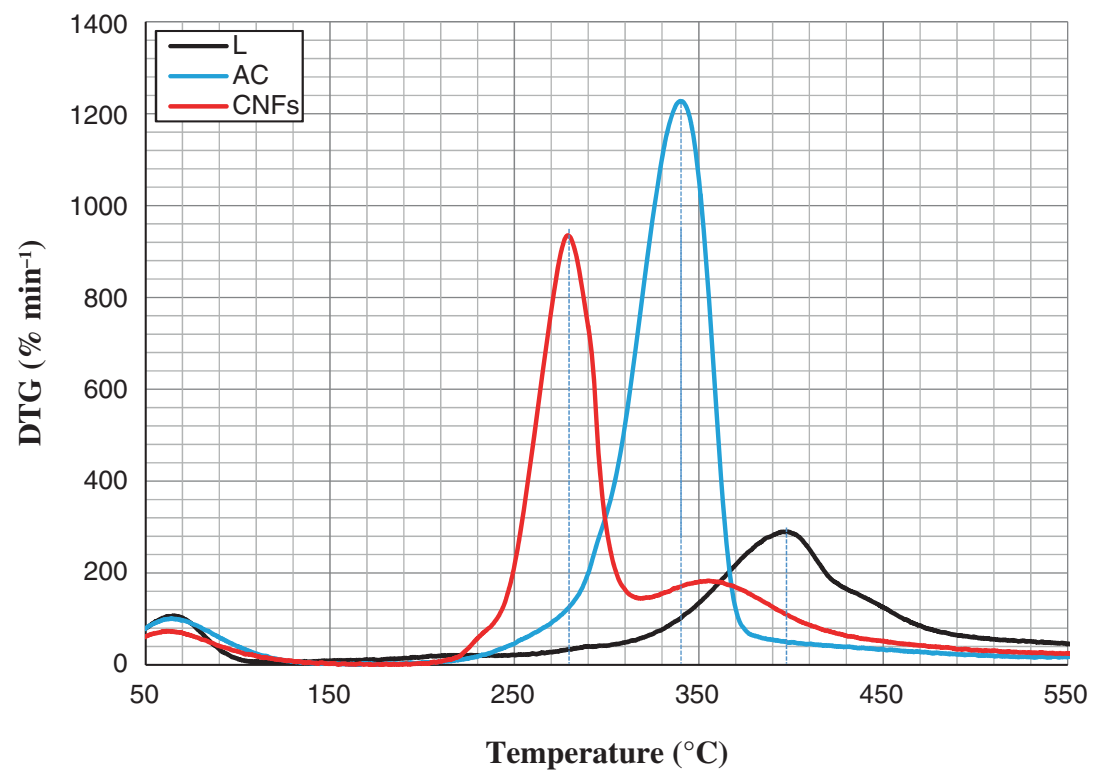

Figure 3. Derivative thermal gravimetry of the bio-fillers during thermal test.

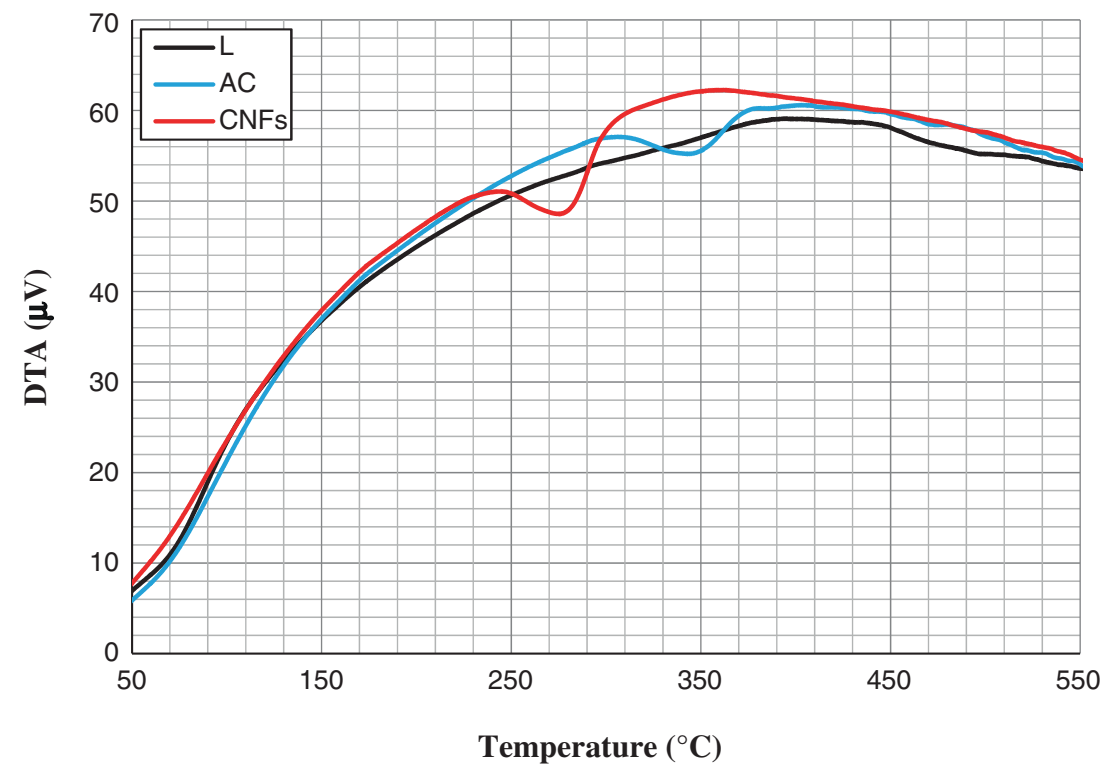

Figure 4. Derivative thermal analysis of bio-fillers during thermal test. 
environmental scanning electron microscopy (ESEM), using a Tescan MAIA3 XMU-SEM, with an accelerating voltage of $5 \mathrm{kV}$. The surface of all samples was sputter-coated with gold using a Denton sputter coater for enhanced conductivity.

2.3d X-ray diffraction analysis (XRD): X-ray diffraction (Rigaku, Japan, 2500V, $\mathrm{CuK} \alpha$ radiation: $1.54056 \AA$ )

Table 3. The summary of TGA, DTG and DTA of the bio-fillers.

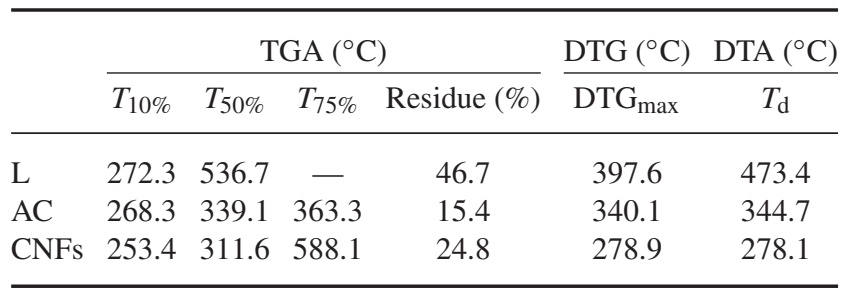

analysis was carried out on both pure PHB and biofillers/PHB biocomposites. The solvent cast films were cut into a size of about $15 \mathrm{~mm} \times 15 \mathrm{~mm}$ and the X-ray diffractograms were recorded in the range $5-55^{\circ}(2 \theta)$ with a step size of $0.04^{\circ}$, and a time per step of $1 \mathrm{~s}$. The same sample holder and the same position of the holder were used for all tests. The crystallinity index (CI) of the powdered samples was calculated as the ratio of the total area under the resolved crystalline peaks to the total area under the unresolved X-ray scattering curve $[23,24]$. CI values were found using the following formula:

$$
\mathrm{CI}(\%)=\frac{\sum A_{\mathrm{c}}}{\sum\left(A_{\mathrm{c}}+A_{\mathrm{a}}\right)},
$$

where $A_{\mathrm{c}}$ is the integrated area underneath the respective crystalline peaks, and $A_{\mathrm{a}}$ is the integrated area of the amorphous halo.

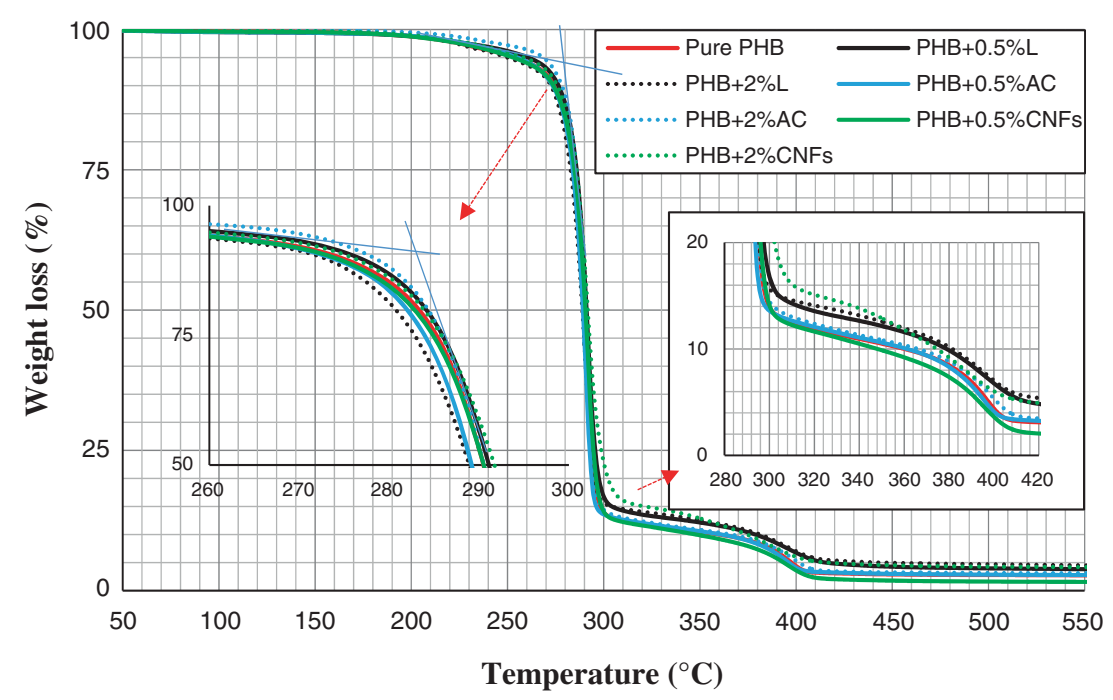

Figure 5. Weight loss percentage of all PHB biocomposites during thermal test.

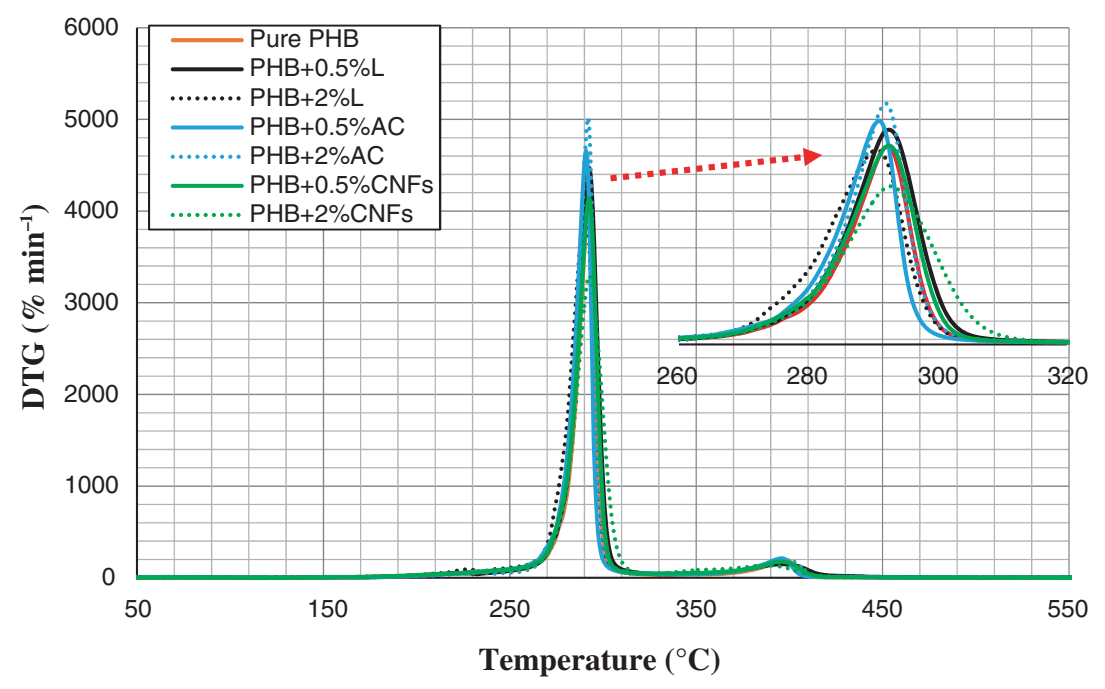

Figure 6. Derivative thermal gravimetry of all PHB biocomposites during thermal test. 
2.3e Fourier transform infrared spectroscopy (FTIR): FTIR was used to determine the changes in the chemical structures of all of the samples. One milligram of the samples was ground into powder with infrared-grade $\mathrm{KBr}$ powder and pressed into a pellet for measurement. Each spectrum was recorded in the range of $700-4000 \mathrm{~cm}^{-1}$ with a resolution of $2 \mathrm{~cm}^{-1}$.

\section{Results and discussion}

The TGA measures the changes in sample mass as a function of the temperature during testing; thermal behaviour of the samples was determined with the changes in the sample mass. Thermal degradation behaviour of PHB composites with bio-filler concentrations of 0.5 and $2 \%$ was researched using TGA. Figures 2, 3 and 4 show the TGA, DTG and TDA thermograms, respectively, of pure L, AC and CNFs. Table 3 also shows a summary of the thermal properties. For the TGA curves of the L, AC and CNFs, low weight loss was detected over the temperature range of $50-230^{\circ} \mathrm{C}$ because of evaporation of the bounded water in the bio-fillers. The first $T_{\text {onset }}$ was found to be $250.8^{\circ} \mathrm{C}$ for CNFs, and $T_{\text {onset }}$ for $\mathrm{AC}$ and $\mathrm{L}$ were found to be 295.5 and $340.8^{\circ} \mathrm{C}$, respectively.
As seen as table 3 , the best stability of fillers was determined for L. $T_{10 \%}$ and $T_{50 \%}$ of $\mathrm{L}$ were found to be 272.3 and $536.7^{\circ} \mathrm{C}$, respectively. $T_{75 \%}$ of $\mathrm{L}$ was not determined because it exhibited the maximum degradation at $550^{\circ} \mathrm{C}$. $T_{10 \%}$ and $T_{50 \%}$ of $\mathrm{AC}$ and CNFs were determined to be 268.3, 253.4 and $339.1,311.6^{\circ} \mathrm{C}$, respectively. According to the weight loss, the maximum degradation was found to be $74.6 \%$ for $\mathrm{AC}$; however, the minimum degradation was measured as $53.3 \%$ for L. DTG curves showed the maximum degradation at $397.6^{\circ} \mathrm{C}$ for $\mathrm{L}$, and DTA peak for $\mathrm{L}$ was obtained at $473.4^{\circ} \mathrm{C}$. The TGA-DTG curves of the PHB composites in figures 5 and 6 exhibit three different degradation stages: (1) in the range of $60-200^{\circ} \mathrm{C}$ with weight loss of $1.5-2 \%$; this mass loss may be attributed to vaporization of water; the free water is evaporated below $100^{\circ} \mathrm{C}$ but linked water that forms physical bounds with polymers is evaporated only above $100^{\circ} \mathrm{C}$; (2) in the range of $200-320^{\circ} \mathrm{C}$ as a result of thermal degradation of PHB main chains and (3) in the range of $320-420^{\circ} \mathrm{C}$ due to the thermal degradation of the bio-fillers.

DTA curves showed the two peaks of melting peak $\left(T_{\mathrm{m}}\right)$ and decomposition peak $\left(T_{\mathrm{d}}\right)$. From figure 7 , the maximum value of $T_{\mathrm{m}}$ was found for the PHB composites with $2 \% \mathrm{AC}$, whereas the minimum value of $T_{\mathrm{m}}$ was determined for the

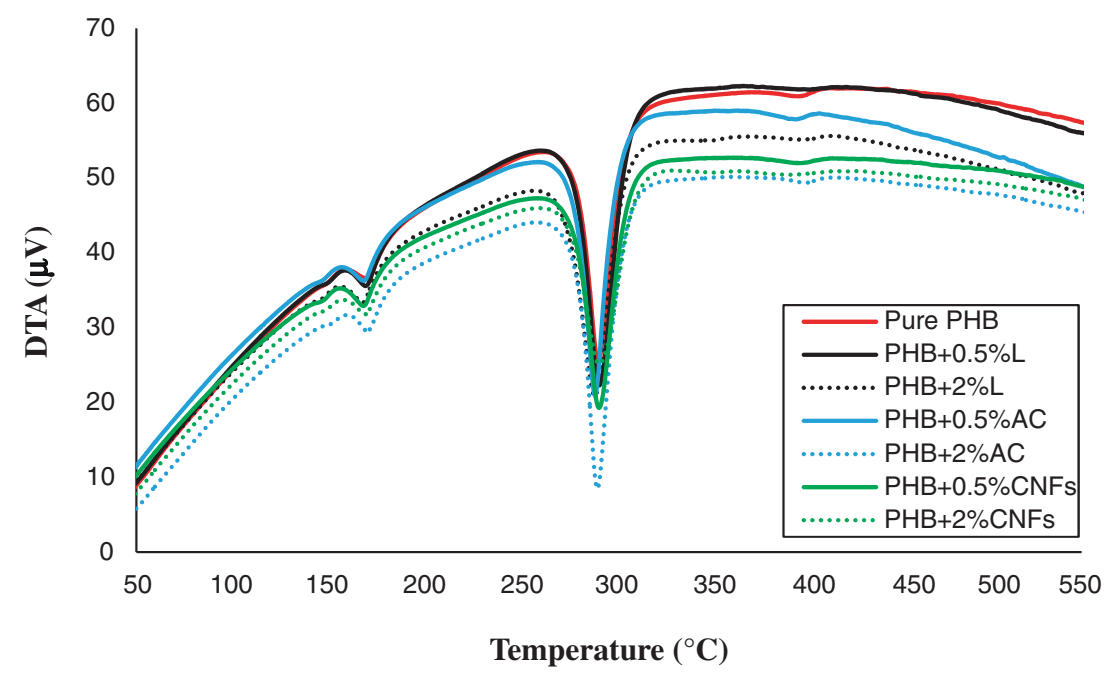

Figure 7. Derivative thermal analysis of all PHB biocomposites during thermal test.

Table 4. The summary of TGA-DTG and DTA of the all PHB biocomposites.

\begin{tabular}{lccccccc}
\hline & \multicolumn{5}{c}{ TGA $\left({ }^{\circ} \mathrm{C}\right)$} & \multirow{2}{*}{${\text { DTG }\left({ }^{\circ} \mathrm{C}\right)}^{2}$} & \multicolumn{2}{c}{ DTA $\left({ }^{\circ} \mathrm{C}\right)$} \\
\cline { 2 - 4 } & $T_{10 \%}$ & $T_{50 \%}$ & $T_{90 \%}$ & Residue $(\%)$ & DTG $_{\max }$ & $T_{\mathrm{m}}$ & $T_{\mathrm{d}}$ \\
\hline Pure PHB & 274.6 & 290.4 & 360.2 & 2.7 & 292.3 & 172.1 & 294.8 \\
PHB+0.5\%L & 276.5 & 291.1 & 378.9 & 3.5 & 292.5 & 171.8 & 295.2 \\
PHB+2\%L & 272.6 & 288.9 & 381.5 & 4.4 & 290.6 & 170.2 & 295.9 \\
PHB+0.5\%AC & 273.4 & 289.2 & 361.4 & 2.8 & 290.9 & 170.7 & 292.6 \\
PHB+2\%AC & 278.2 & 290.5 & 366.2 & 3.1 & 291.9 & 172.4 & 293.9 \\
PHB+0.5\%CNFs & 273.9 & 290.4 & 348.4 & 1.6 & 292.2 & 170.6 & 294.8 \\
PHB+2\%CNFs & 275.8 & 291.7 & 374.6 & 4.2 & 292.3 & 171.4 & 295.6 \\
\hline
\end{tabular}


PHB composites with $2 \% \mathrm{~L}$. As regards $T_{\mathrm{d}}$ values, the maximum and minimum values were found for $0.5 \% \mathrm{AC}$ and $2 \% \mathrm{~L}$, respectively.

From the summary of the thermal analysis given in table 4, it was found that the largest residues were for PHB composites with $0.5 \% \mathrm{~L}$ and $2 \% \mathrm{~L}$. The highest values of $T_{10 \%}$, $T_{50 \%}$ and $T_{75 \%}$ were measured in $\mathrm{PHB}+2 \% \mathrm{AC}$ as $278.2^{\circ} \mathrm{C}$, $\mathrm{PHB} 0.5 \% \mathrm{~L}$ as $291.1^{\circ} \mathrm{C}$ and $\mathrm{PHB}+2 \% \mathrm{~L}$ as $381.5^{\circ} \mathrm{C}$, respectively. The largest value of the $\mathrm{DTG}_{\max }$ was found to be $292.5^{\circ} \mathrm{C}$ for $\mathrm{PHB}+0.5 \% \mathrm{~L}$.

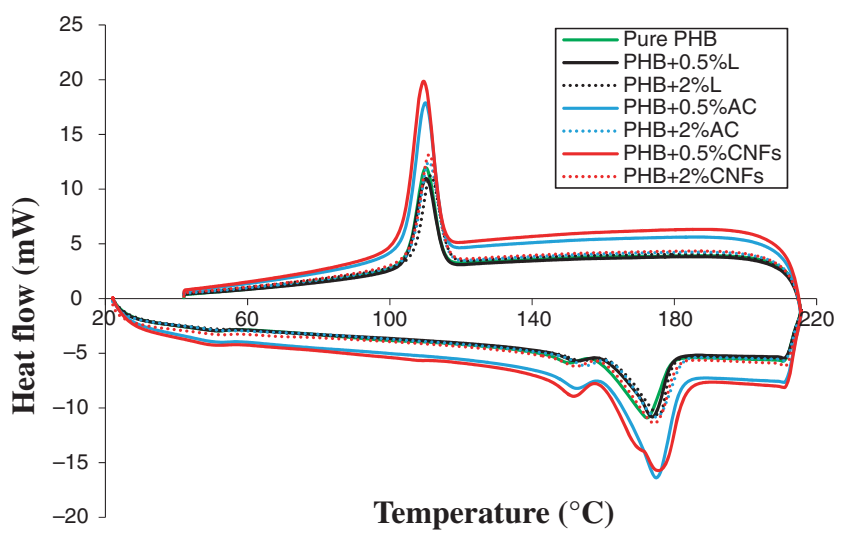

Figure 8. Thermal isotherms for first heating and cooling of the PHB biocomposites.

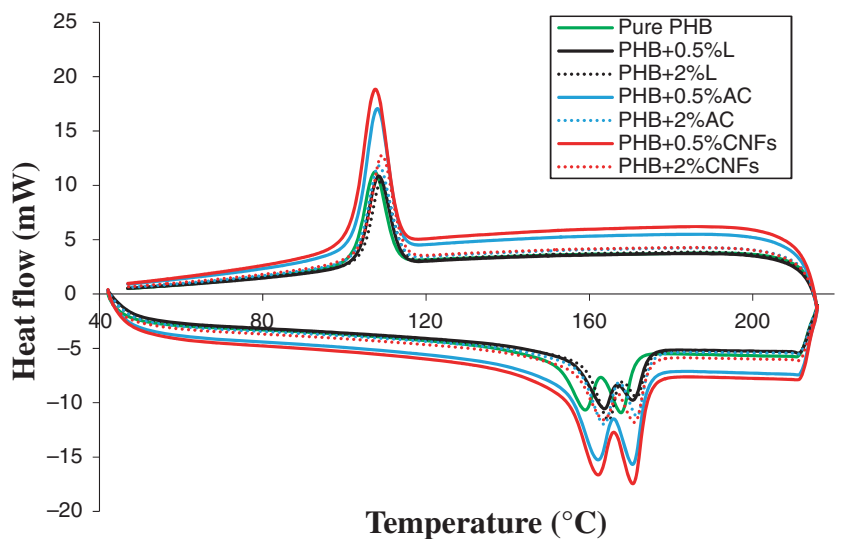

Figure 9. Thermal isotherms for second heating and cooling of the PHB biocomposites.
As a result, lignin has the best thermal stability in the biofillers according to the TGA analysis, and the addition of $\mathrm{L}$ improved the thermal stability of the PHB composites; it can be said that the $\mathrm{L}$ particles can be used for thermal retardancy in polymer matrix. Figures 8 and 9 show the DSC for 1 st and 2 nd heating/cooling of the PHB composites with 0.5 and 2 wt $\%$ bio-fillers L, AC and CNFs.

DSC analysis was carried out to investigate the effect of $\mathrm{L}$, $\mathrm{AC}$ and $\mathrm{CNF}$ s on the PHB matrix. The crystallization temperature $\left(T_{\mathrm{c}}\right)$, crystallization enthalpy $\left(\Delta H_{\mathrm{c}}\right)$, melting point $\left(T_{\mathrm{m}}\right)$, melting enthalpy $\left(\Delta H_{\mathrm{m}}\right)$ and crystallinity $\left(X_{\mathrm{c}}\right)$ were measured for pure PHB and the PHB biocomposites after 1st and 2nd heating/cooling. As shown in table 5, pure PHB has a melting peak and a crystallinity peak at 172.4 and $109.8^{\circ} \mathrm{C}$, respectively. When $\mathrm{PHB}$ was blended with the bio-fillers, the peaks of the PHB composites exhibited a double melting peak at 155 and $175^{\circ} \mathrm{C}$. The double melting peaks for the PHB after loading with various fillers were determined in the studies [25,26] and attributed to a bimodal distribution of crystallite size resulting from changes in molecular weight due to random scission of long PHB chains, i.e., to the decrease in the molecular weight [26]. $T_{\mathrm{c}}$ and $T_{\mathrm{m}}$ for all PHB composites were in the range of 109-112 and 172$177^{\circ} \mathrm{C}$, respectively. An improvement in $T_{\mathrm{c}}$ and $T_{\mathrm{m}}$ value was observed by incorporation of bio-fillers into PHB (table 5). $T_{\mathrm{c}}$ and $T_{\mathrm{m}}$ values in $1 \mathrm{st}$ heating/cooling were found to be higher than the values obtained after 2nd heating/cooling. Melting and crystallization enthalpies changed, respectively, from 57.4 to 66.1 and 46.1 to $51.9 \mathrm{~J} \mathrm{~g}^{-1}$ after filling with biofillers of PHB matrix. Both enthalpies were found to be lower at 2 nd heating/cooling as compared with the values obtained with fist heating/cooling. The crystallinity $\left(X_{\mathrm{c}}\right)$ was determined to range from 39.3 to 45.3 and from 35.4 to $41.7 \%$ for first and second heating/cooling, respectively.

SEM studies were conducted to investigate the dispersion of L, AC and CNFs in the PHB matrix and SEM micrographs are shown in figure 10. SEM images in figure $10 \mathrm{~b}$ and $\mathrm{c}$ show the dispersion of PHB with AC. The interface between $\mathrm{AC}$ and matrix was found to be poor because of large pores, and there are no connections between $\mathrm{AC}$ and the polymer matrix. Pores were also observed on the PHB biocomposites with $\mathrm{L}$ and CNFs. Absence of the pores is related to the high viscosity and toughness of the PHB matrix [27]. The L and

Table 5. The summary of DSC analysis of the all PHB biocomposites.

\begin{tabular}{|c|c|c|c|c|c|c|c|c|c|c|}
\hline \multirow[b]{3}{*}{ Samples } & \multicolumn{4}{|c|}{ Cooling } & \multicolumn{4}{|c|}{ Heating } & & \\
\hline & \multicolumn{2}{|c|}{$T_{\mathrm{c}}\left({ }^{\circ} \mathrm{C}\right)$} & \multicolumn{2}{|c|}{$\Delta H_{\mathrm{c}}\left(\mathrm{J} \mathrm{g}^{-1}\right)$} & \multicolumn{2}{|c|}{$T_{\mathrm{m}}\left({ }^{\circ} \mathrm{C}\right)$} & \multicolumn{2}{|c|}{$\Delta H_{\mathrm{m}}\left(\mathrm{J} \mathrm{g}^{-1}\right)$} & \multicolumn{2}{|c|}{$X_{\mathrm{c}}(\%)$} \\
\hline & $1 \mathrm{st}$ & 2nd & $1 \mathrm{st}$ & 2nd & $1 \mathrm{st}$ & 2nd & $1 \mathrm{st}$ & 2nd & $1 \mathrm{st}$ & 2nd \\
\hline Pure PHB & 109.8 & 107.4 & 49.6 & 49.6 & 172.4 & 167.8 & 64.8 & 60.8 & 44.5 & 41.6 \\
\hline $\mathrm{PHB}+0.5 \% \mathrm{~L}$ & 110.6 & 108.6 & 46.1 & 45.6 & 174.1 & 170.9 & 57.4 & 51.6 & 39.3 & 35.4 \\
\hline $\mathrm{PHB}+2 \% \mathrm{~L}$ & 111.5 & 109.5 & 51.9 & 51.4 & 176.2 & 171.7 & 66.1 & 59.7 & 45.3 & 40.1 \\
\hline $\mathrm{PHB}+0.5 \% \mathrm{AC}$ & 110.4 & 108.3 & 49.9 & 48.7 & 174.5 & 170.6 & 64.8 & 60.9 & 44.5 & 41.7 \\
\hline $\mathrm{PHB}+2 \% \mathrm{AC}$ & 111.5 & 108.1 & 49.5 & 49.3 & 175.4 & 171.9 & 65.4 & 56.2 & 44.8 & 38.5 \\
\hline $\mathrm{PHB}+0.5 \% \mathrm{CNFs}$ & 109.8 & 107.6 & 49.3 & 48.7 & 176.1 & 170.9 & 61.6 & 55.6 & 42.3 & 38.1 \\
\hline $\mathrm{PHB}+2 \% \mathrm{CNFs}$ & 111.3 & 109.5 & 50.7 & 50.6 & 174.5 & 171.3 & 65.8 & 57.4 & 45.1 & 39.5 \\
\hline
\end{tabular}



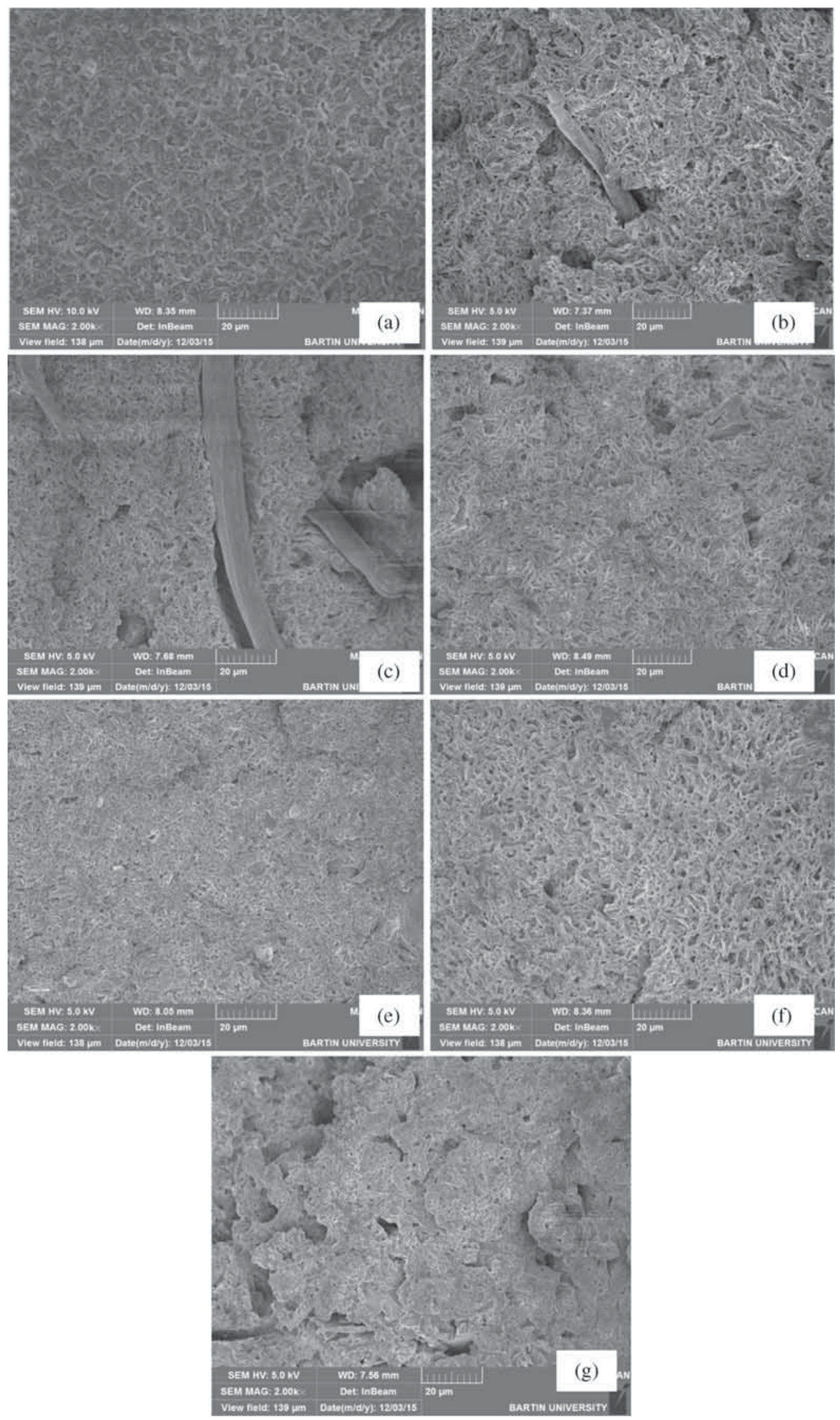

Figure 10. SEM images of the PHB biocomposites. (a) Pure PHB, (b) $0.5 \%$ AC and (c) $2 \%$ AC, (d) $0.5 \% \mathrm{~L}$, (e) $2 \% \mathrm{~L}$, (f) $0.5 \% \mathrm{CNFs}$ and (g) $2 \% \mathrm{CNFs}$. 


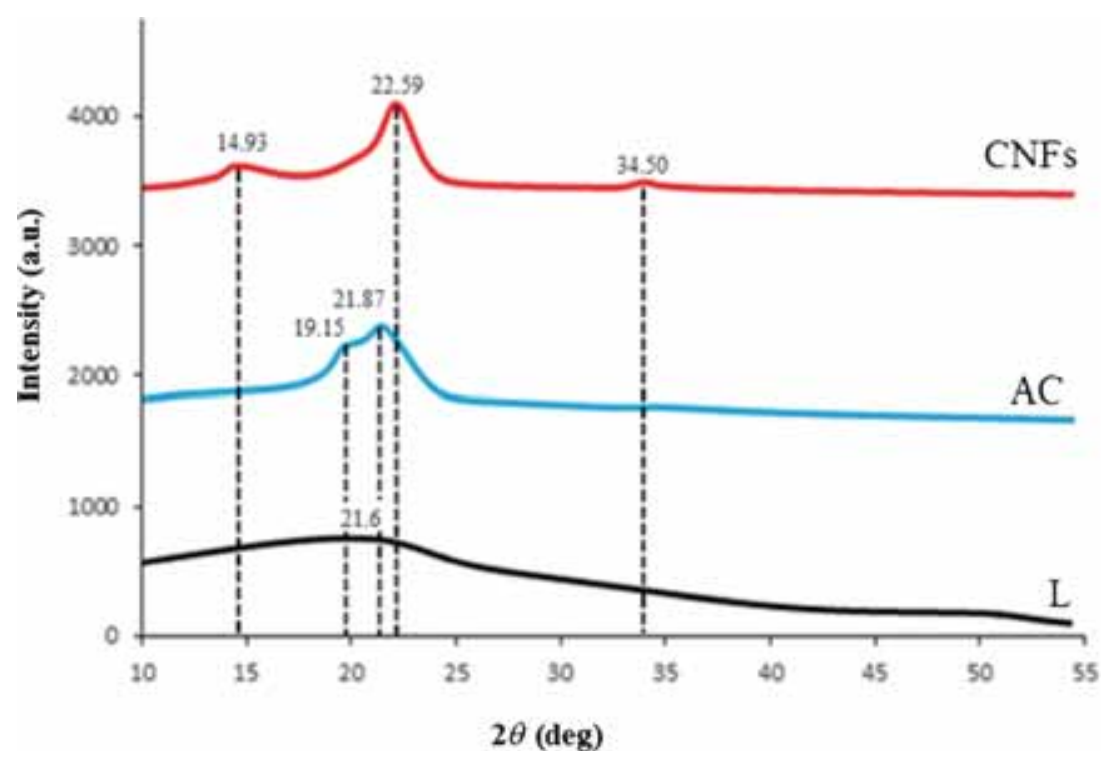

Figure 11. XRD patterns of the bio-fillers.

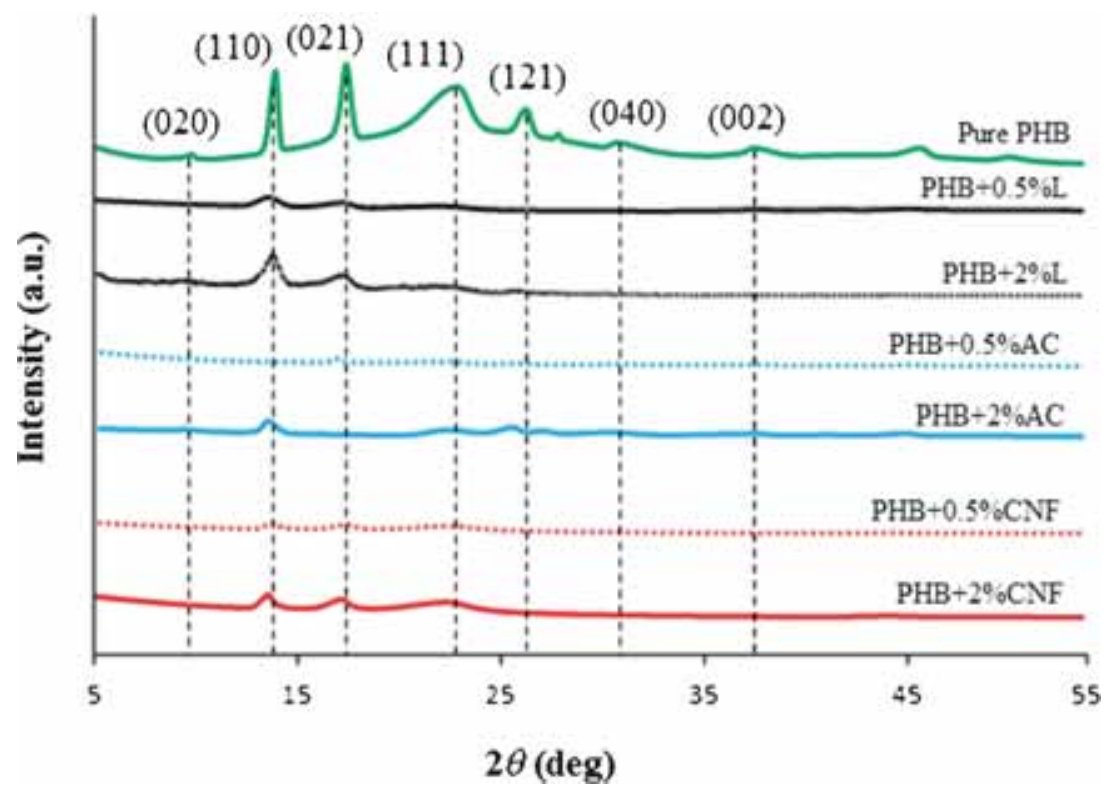

Figure 12. XRD patterns of the PHB biocomposites.

CNFs were homogenously dispersed in PHB matrix, and the sizes of the pores in PHB matrix were smaller than in the PHB biocomposites with AC.

The XRD patterns of bio-fillers determined in the range $10-55^{\circ}$ are shown in figure 11 . The patterns show peaks at $21.6^{\circ}$ for $\mathrm{L}, 19.15$ and $21.87^{\circ}$ for $\mathrm{AC}$, and $14.93,22.59$ and $34.50^{\circ}$ for CNFs. There was a small peak at $35.2^{\circ}$ for AC, but it is not visible in figure 11 . The peaks generally match with those in other studies in the literature [28-31].

The XRD patterns of PHB in the range $5-55^{\circ}$ show six main peaks (centred at $2 \theta=13.57,16.87,22.1,25.6,27.2$ and $36.7^{\circ}$ attributed to the $020,110,021,111,121,040$ and 002 planes). XRD patterns of PHB biocomposites showed
Table 6. Crystallinity index of the all PHB biocomposites.

\begin{tabular}{lc}
\hline Samples & CI $(\%)$ \\
\hline L & 27.9 \\
AC & 60.2 \\
CNFs & 59.7 \\
Pure PHB & 43.1 \\
PHB+0.5\%L & 38.2 \\
PHB+2\%L & 39.5 \\
PHB+0.5\%AC & 44.5 \\
PHB+2\%AC & 44.8 \\
PHB+0.5\%CNFs & 34.7 \\
PHB+2\%CNFs & 31.5 \\
\hline
\end{tabular}




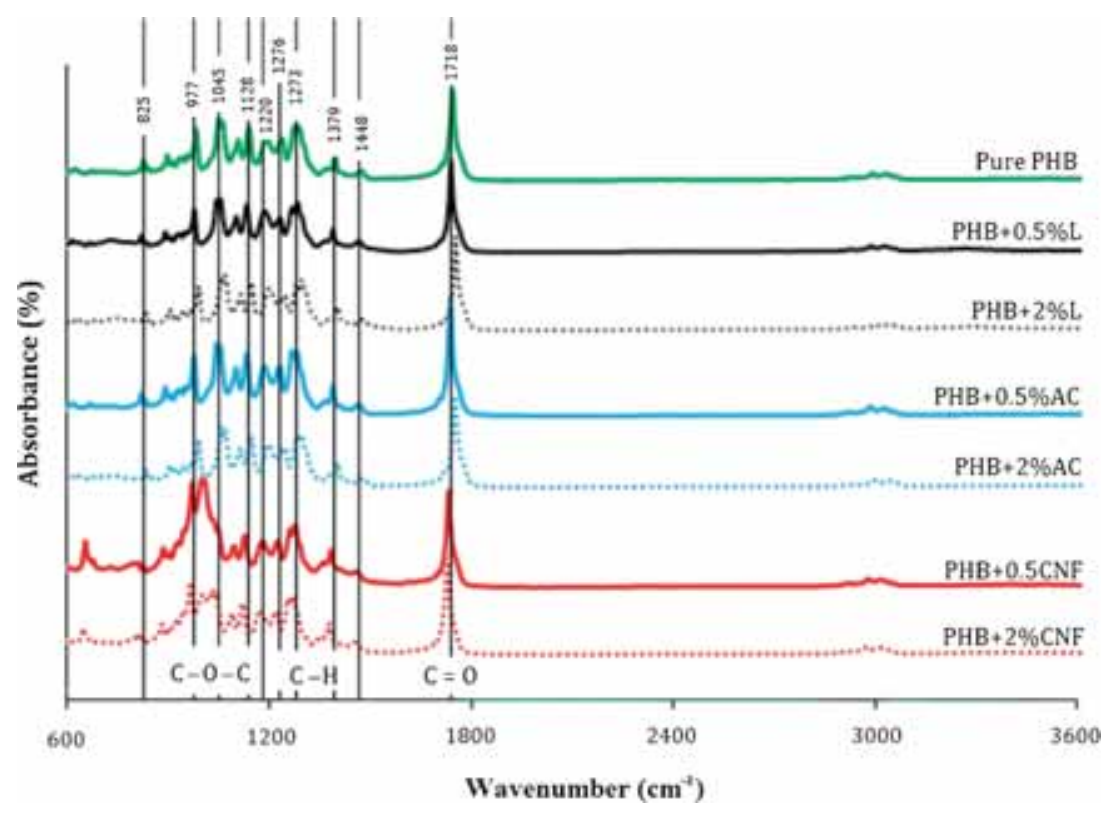

Figure 13. The FTIR spectra of the PHB and its biocomposites with different loadings of bio-fillers in the region from 600 to $3600 \mathrm{~cm}^{-1}$.

three main peaks at $13.57,16.87$ and $22.1^{\circ}$, and the other peaks disappeared in the patterns. Crystalline index (\%) was calculated according to Rabiej $[23,24]$ and the values are shown in figures 11 and 12 . Table 6 shows the crystallinity index $\left(X_{\mathrm{c}}\right)$ of the bio-fillers and PHB biocomposites. From table $4, X_{\mathrm{c}}$ is found to be $27.9 \%$ for $\mathrm{L}, 59.7 \%$ for $\mathrm{CNFs}$ and $60.2 \%$ for AC. In the PHB composites, the crystallinity index was measured to range from 31.5 to $44.8 \%$. The largest and lowest values of $X_{\mathrm{c}}$ were found for PHB $+2 \% \mathrm{AC}$ and PHB $+2 \%$ CNFs, respectively.

FTIR spectra from 600 to $3600 \mathrm{~cm}^{-1}$ are shown for PHB with the bio-fillers such as $\mathrm{AC}, \mathrm{CNFs}$ and L (figure 13). The band found at $1,721 \mathrm{~cm}^{-1}$ is due to the carbonyl group $(\mathrm{C}=\mathrm{O})$ of PHB and PHB biocomposites. Peaks at 1,384, $1,128,1,091$ and $1,052 \mathrm{~cm}^{-1}$ correspond to the amorphous phase of PHB and bands at 1,275, 1,261, 1,224, 1,182 and $1,046 \mathrm{~cm}^{-1}$ arise from the crystalline phase. The bands at $1,261,1,224,1,182$ and $1,046 \mathrm{~cm}^{-1}$ correspond to the C$\mathrm{O}-\mathrm{C}$ stretching modes of the crystalline components. The band at $1,372 \mathrm{~cm}^{-1}$ is assigned to the symmetric deformation mode of the $\mathrm{CH}_{3}$ group and the band at $822 \mathrm{~cm}^{-1}$ is attributed to $\mathrm{CH}_{3}$ bending in PHB $[2,32,33]$.

FTIR spectra show that the peaks of carbonyl group and other characteristic peaks in biocomposites are changed to higher or lower wavenumbers. The peaks at 1.379 and $1.448 \mathrm{~cm}^{-1}$ are assigned, respectively, to $-\mathrm{C}-\mathrm{H}-$ deformation including symmetric and asymmetric bends, while the peaks at 1.273, 1.276, 1.220, 1.128, 1.045, 977 and $825 \mathrm{~cm}^{-1}$ are attributed to $-\mathrm{C}-\mathrm{O}-\mathrm{C}-$ stretches. In this study, some changes near the $-\mathrm{C}-\mathrm{H}-$ peak were also observed, i.e., some hydrogen bonding in PHB composites as indicated by shifted peaks $\left(1.379\right.$ and $\left.1.718 \mathrm{~cm}^{-1}\right)$. There are changes in intensities for $\mathrm{C}=\mathrm{O},-\mathrm{C}-\mathrm{O}-\mathrm{C}-$ and $-\mathrm{C}-\mathrm{H}-$ bands (e.g., 1.220,
1.273 and $1.276 \mathrm{~cm}^{-1}$ ), which could be indicators of changes in crystallinity ratios. The $\mathrm{C}-\mathrm{H}$ group located at 2933.87 and $2978.11 \mathrm{~cm}^{-1}$ reflects lipid nature of PHB, such as symmetric-asymmetric stretching band of methyl-methylene [1].

\section{Conclusions}

In this work, the effects of the bio-fillers such as L, AC and CNFs on the thermal, morphological and structural properties of PHB were observed by TGA, DSC, SEM, XRD and FTIR. The addition of the bio-fillers improved the thermal behaviour, and improving effect of $\mathrm{L}$ was found to be higher than those of the other fillers. $T_{\mathrm{c}}$ and $T_{\mathrm{m}}$ values increased with incorporation of bio-fillers into PHB, and $T_{\mathrm{c}}$ and $T_{\mathrm{m}}$ for 1 st heating/cooling were found to be higher than the values obtained after 2nd heating/cooling. SEM images showed that interactions between filler and matrix were found to be poor because of large pores. But the pores in the PHB biocomposites with $\mathrm{L}$ and $\mathrm{CNFs}$ were found to smaller than in the PHB biocomposites with $\mathrm{AC}$. In XRD patterns, $\mathrm{L}$ has lower crystallinity in comparison with the AC and CNFs. The structural properties of the PHB biocomposites were observed to be similar from XRD and FTIR analysis.

\section{References}

[1] Liau C P, Ahmad M, Shameli K, Yunus W Z, Ibrahim N A, Zainuddin N and Then Y Y 2014 E-Sci. World J. Article ID 572726 (9 p)

[2] El-Hadi A M 2014 Polym. Bull. 711449

[3] Erkskea D, Viskerea I, Dzenea A, Tupureinaa V and Savenkovab L 2006 Proc. Estonian Acad. Sci. Chem. 5570 
[4] Sridhar V, Lee I, Chun H H and Park H 2013 eXPRESS Polym. Lett. 7320

[5] Seoane I T, Manfredi L B and Cyras V P 2015 Proc. Mater. Sci. 8807

[6] Sudesh K and Doi Y 2005 in Bastioli C (ed) Handbook of biodegradable polymers (Shawbury: Rapra Technology Ltd) p 219

[7] Sanchez-Garcia M D, Gimenez E and Lagaron J M 2008 J. Appl. Polym. Sci. 1082787

[8] Cyras V P, Vazquez A, Rozsa C, Fernandez G N, Torre L and Kenny J M 2000 J. Appl. Polym. Sci. 772889

[9] Bucci D, Tavares L and Sell I 2005 Polym. Test. 24564

[10] Bordes P, Pollet E and Avérous L 2009 Prog. Polym. Sci. 34125

[11] Fernandes E G, Pietrini M and Chiellini E 2004 Biomacromolecules $\mathbf{5} 1200$

[12] Singh S and Mohanty A K 2007 Compos. Sci. Technol. 671753

[13] Tănasea E E, Popaa M E, Râpă M B and Popaa O 2015 Agric. Agric. Sci. Procedia 6608

[14] Chan R T H, Garvey C J, Marcal H, Russell R A, Holden P J and Foster J F R 2011 Int. J. Polym. Sci. Article ID 651549 (8 p)

[15] Bhardwaj R, Mohanty A K, Drzal L T, Pourboghrat F and Misra M 2006 Biomacromolecules 72044

[16] Christiana S J and Billington S L 2011 Compos. Part B: Eng. 421920

[17] El-Hadi A M 2013 Colloid Polym. Sci. 291743

[18] Jiang L, Morelius E, Zhang J, Wolcott M and Holbery J 2008 J. Compos. Mater. 422629
[19] Vila C, Campos A R, Cristovao C, Cunha A M, Santos V and Parajo J C 2000 Compos. Sci. Technol. 68944

[20] Ren H, Liu Z, Zhai H, Cao Y and Omori S 2015 BioResources 10432

[21] Azizi Samir M A S, Alloin F and Sanchez A 2004 Polymer 454149

[22] Kiziltas A, Gardner D J, Han Y and Yang H 2011 Thermochimica $\mathbf{5 1 9} 38$

[23] Rabiej M 2003 Fibers Text. East. Eur. 1183

[24] Rabiej S 1991 Eur. Polym. J. 27947

[25] Seggiania M, Cinelli P, Verstichelc S, Puccinia M, Vitoloa S, Anguillesia I and Lazzeria A 2015 Chem. Eng. Trans. 431813

[26] Erceg M, Kovacic T and Klaric I 2005 Polym. Deg. Stab. 90313

[27] Ren H, Liu Z, Zhai Z M, Cao Y and Omori S 2015 BioResources 10432

[28] Hamada Y, Yoshida K, Asai R, Hayase S, Nokami T, Izumi S and Itoh T 2013 Green Chem. 151863

[29] Goudarzi A, Lin L and Ko F K 2014 J. Nanotechnol. Eng. Med. 51

[30] Lionetto F, Sole R, Cannoletta D, Vasapollo G and Maffezzoli A 2012 Materials 51910

[31] Aydemir D, Kiziltas A, Kiziltas E E, Gardner D and Gunduz G 2015 Compos. Part B 68414

[32] Bloembergen S and Holden D A 1986 Macromolecules 192865

[33] Padermshoke A, Katsumoto Y, Sato H, Ekgasit S, Noda I and Ozaki Y 2005 Spectrochim. Acta Part A: Mol. Biomol. Spectrosc. 61541

[34] Doi Y 1990 Microbial polyesters (New York: VHC Publishing) p 101 